\title{
Aflatoxin Carryover during Large Scale Peanut Butter Production
}

\author{
Andrew H. Siwela ${ }^{1}$, Kudzayishe J. Mukaro ${ }^{1}$, Nozipo Nziramasanga ${ }^{2}$ \\ ${ }^{1}$ Department of Applied Biology and Biochemistry, National University of Science and Technology, Ascot, Bulawayo, Zimbabwe; \\ ${ }^{2}$ Special Analysis Laboratory, Chemistry and Soils Research Institute, Agricultural Research and Extension, Causeway, Harare, \\ Zimbabwe. \\ E-mail: asiwela@nust.ac.zw, ahsiwela@gmail.com
}

Received February $16^{\text {th }}, 2011$; revised February $24^{\text {th }}$, 2011; accepted March $4^{\text {th }}, 2011$.

\begin{abstract}
Peanut butter was monitored for aflatoxin contamination at different stages during its large-scale production starting from raw shelled peanuts up to the final product. Twenty five samples, weighing $2 \mathrm{~kg}$ each, were taken from each of the following stages: roasting at $160^{\circ} \mathrm{C}$, blanching/de-skinning and grinding. The sub-samples were ground, thoroughly mixed and further reduced by the quartering technique until a $1 \mathrm{~kg}$ sub-sample was obtained. This was then analyzed for aflatoxins using reverse phase HPLC incorporating pre-column trifluoroacetic acid derivatization. The results showed a total aflatoxin percentage reduction of 51\% after roasting, 27\% after blanching/de-skinning followed by a further $11 \%$ after grinding to make peanut butter. This meant that there was a cumulative total reduction of $89 \%$ of aflatoxin concentration during the production process of peanut butter. These results show that there is a significant reduction of aflatoxin levels at the roasting and blanching stages in the process of producing peanut butter.
\end{abstract}

Keywords: Aflatoxin, Roasting, Blanching, Peanut Butter

\section{Introduction}

The discovery of aflatoxin contamination in peanuts dates back to the early 1960s when investigation into the cause of a feed-related aflatoxicosis that killed 100000 turkeys in England was traced to peanut meal constituting the feed [1].

Aflatoxins are a group of closely related secondary toxic metabolites of fungi belonging to the Aspergillus spp. that can grow on raw food commodities including nuts and cereals [2]. The metabolites are named aflatoxin $\mathrm{B}_{1}\left(\mathrm{AFB}_{1}\right)$, aflatoxin $\mathrm{B}_{2}\left(\mathrm{AFB}_{2}\right)$, aflatoxin $\mathrm{G}_{1}\left(\mathrm{AFG}_{1}\right)$ and aflatoxin $\mathrm{G}_{2}\left(\mathrm{AFG}_{2}\right)$.

Acute and chronic toxicity of aflatoxins have been demonstrated in several animal species including birds, fish, domestic animals and primates [3] Cases of human acute aflatoxicosis have been recently been reported in Kenya where an aflatoxicosis outbreak resulted in 125 deaths out of 317 cases [4] in India where 106 deaths were reported out of 400 cases [5] and other places in Asia such as Malaysia [6]

Epidemiological studies of human populations exposed to diets naturally contaminated with aflatoxins revealed an association between the high incidence of liver cancer in
Africa and elsewhere and dietary intake of aflatoxins [7]. In 1993 the International Agency for Research on Cancer (IARC) classified $\mathrm{AFB}_{1}$ and mixtures of aflatoxins as Group 1 carcinogens, i.e. substances that can cause cancer in humans [8]. There is also mounting evidence implicating aflatoxins as an important factor in infant under-nutrition [9] and impaired growth in children under five years old [10]. This has been attributed to aflatoxin suppressing the immune system and absorption of micronutrients [11].

Aflatoxins are quite stable in many foods and are fairly resistant to degradation even during processing. At present, removal or decontamination of aflatoxins is based mainly on physical removal of the contaminated portions, treatment with heat, chemical or radiation techniques [12].

Peanut butter production involves dry roasting raw shelled peanuts at $160^{\circ} \mathrm{C}$, blanching/de-skinning and grinding. Other ingredients such as sugar, salt as well as hydrogenated fat (as a stabilizer) are added. As peanut butter is widely used in children's food such as porridge, sandwiches, etc and the young are the most susceptible to aflatoxin toxic effects [13], we decided to monitor aflatoxin carryover during large scale peanut butter production. 


\section{Materials and Methods.}

Five samples from 5 batches of peanuts, each weighing 2 kg were obtained from the following stages of processing: dry roasting, blanching and grinding. The peanuts had been purchased from local farmers. The samples were ground using a commercial $4 \mathrm{~L}$ Waring blender (Dynamics Corporation of America, New Hartford, Connecticut, USA), thoroughly mixed and further reduced by the quartering technique until a $1 \mathrm{~kg}$ sub-sample was obtained. The sub-sample was then slurried using 1 part meal to 2 parts water [14]. A $100 \mathrm{~g}$ of the slurry of each sample was extracted with $200 \mathrm{ml}$ of acetone and filtered using Whatman No. 4 filter paper. A $5 \mathrm{ml}$ aliquot of the filtrate was mixed with $60 \mathrm{ml}$ of $20 \%$ lead acetate to precipitate proteins and other precipitable materials. and then passed through a $5 \mathrm{mg}$ phenyl-bonded pre-packed column (Bond elut, Varian, Harbor City, USA). The aflatoxins were then eluted from the phenyl bonded column using $7 \mathrm{ml}$ chloroform into an $8 \mathrm{ml}$ vial. The chloroform was evaporated and the residue derivatized using trifluoroacetic acid (TFA). The TFA was then evaporated and the residue reconstituted in 25\% aqueous acetonitrile. Analyses were performed using an HPLC (Phillips PU 4100M; Cambridge, UK) with manual injections of $20 \mu \mathrm{l}$ aliquots of sample alongside standard solutions as described by Siwela [15]. Isocratic elution of the toxins was done using aqueous acetonitrile (25\%) at a flow rate of 1 $\mathrm{ml} / \mathrm{min}$. The separation column (5 $\mu \mathrm{m}$ Spherisorb ODS, $12.5 \mathrm{~cm} \times 4 \mathrm{~mm}$ i.d.) was maintained at $40^{\circ} \mathrm{C}$ in a heating block. The toxins were detected using a Philips PU 4027 fluorescent detector set at wavelengths $365 \mathrm{~nm}$ for excitation and $418 \mathrm{~nm}$ for emission, the signals being recorded on an electronic integrator (Varian 4400; Walnut Creek, USA). The concentrations of aflatoxins were calculated by comparing peak heights with those of standard solutions.

\section{Statistical Analysis}

Results were expressed as means \pm standard deviation (SD). Statistical analysis (Student's t test) was performed using GraphPad Instat software (Graph Pad Prism, San Diego, California, USA).

\section{Results}

Results from our previous recovery studies on five samples spiked with individual aflatoxins at $5 \mathrm{ng} \mathrm{g}^{-1}$ showed a mean total aflatoxin recovery of $81.9 \pm 1.8 \%$ whilst $91.7 \pm 3.8 \%$ was the mean recovery for those samples spiked with $20 \mathrm{ng} \mathrm{g}^{-1}$ individual aflatoxins [15].

Figure 1 shows the progressive reduction of aflatoxin concentrations at different stages of processing. There was a statistically significant reduction of $\mathrm{AFB}_{1}$ and

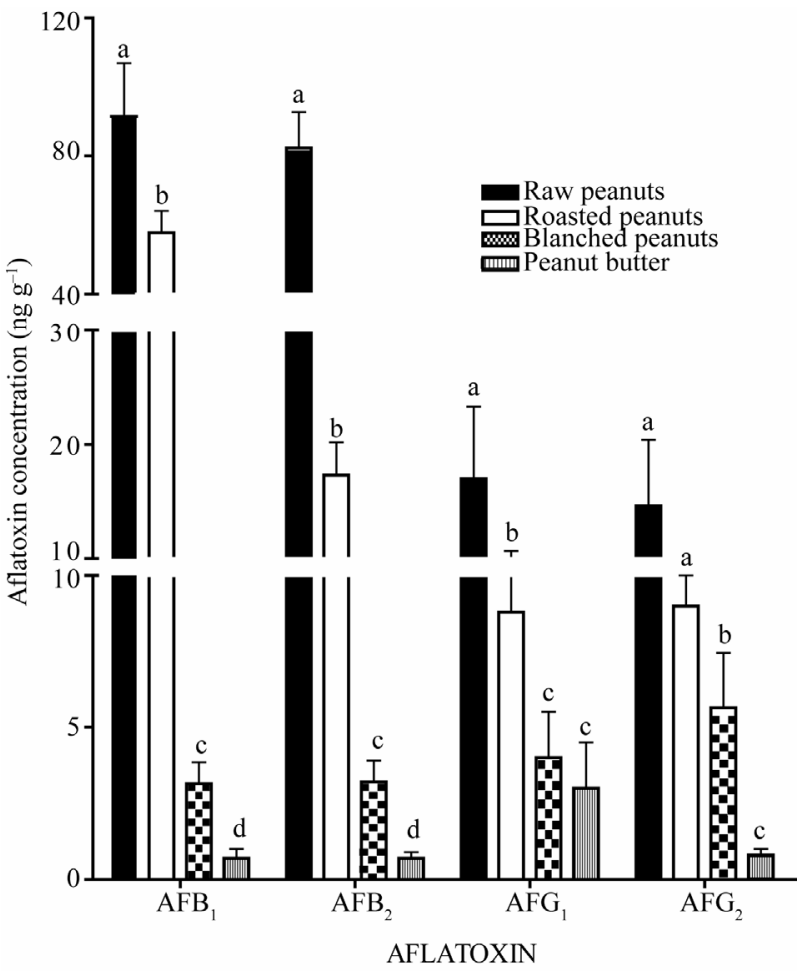

Figure 1. Mean aflatoxin concentrations at different stages of processing in the production of peanut butter. Different letters above vertical bars for each aflatoxin indicate that concentrations are significantly different from each other, Student's t test, $\mathrm{p}<0.05$.

$\mathrm{AFB}_{2}$ concentrations at every stage of production ( $\mathrm{p}<$ $0.01)$. Significant reductions in the concentration of $\mathrm{AFG}_{1}$ were noted at the roasting and blanching stages ( $\mathrm{p}$ $<0.05$ ) but not at the grinding stage ( $>0.05)$. The reduction in the concentration of $\mathrm{AFG}_{2}$ was not quite significant ( $p=0.066$ ) though significant at the blanching and grinding stages $(\mathrm{p}<0.05)$.

The calculated percentages of aflatoxin reduction for each processing stage are shown in Table 1. On average, roasting achieved a $51 \%$ reduction of total aflatoxin. The reduction was in the order $\mathrm{AFG}_{1}(79 \%)>\mathrm{AFB}_{2}$ (48\%) > $\mathrm{AFG}_{2}(38 \%)>\mathrm{AFB}_{1}$ (37\%). Blanching achieved a mean $27 \%$ total aflatoxin reduction which was in the order $\mathrm{AFB}_{1}(57 \%)>\mathrm{AFB}_{2}(27 \%)>\mathrm{AFG}_{2}(23 \%)>\mathrm{AFG}_{1}$ (17\%). Except for $\mathrm{AFG}_{1}$ (33\% reduction), the lowest reduction was achieved by grinding whose mean total aflatoxin reduction was $11 \%$. $\mathrm{AFB}_{2}$ was reduced by $6 \%$ whilst $\mathrm{AFB}_{1}$ and $\mathrm{AFB}_{2}$ were reduced by $3 \%$ respectively.

\section{Discussion}

Aflatoxins have a melting point ranging from $237^{\circ} \mathrm{C}$ to $289^{\circ} \mathrm{C}$ in their dry form [16] and may be partially destroyed by both dry roasting $[17,18]$ or cooking $[19,20]$. 
Table 1. Percentage reduction of aflatoxins during different stages of large scale peanut butter production.

\begin{tabular}{cccccc}
\hline \multirow{2}{*}{ Process } & \multicolumn{5}{c}{ Percent aflatoxin reduction } \\
\cline { 2 - 6 } & $\mathrm{AFB}_{1}$ & $\mathrm{AFB}_{2}$ & $\mathrm{AFG}_{1}$ & $\mathrm{AFG}_{2}$ & Total \\
\hline Roasting & 37 & 79 & 48 & 38 & 51 \\
Blanching & 57 & 17 & 27 & 23 & 27 \\
Grinding & 3 & 3 & 6 & 33 & 11 \\
$\begin{array}{c}\text { Total Percent } \\
\text { aflatoxin reduction }\end{array}$ & 97 & 99 & 81 & 94 & 89 \\
\hline
\end{tabular}

$\mathrm{AFT}^{*}=$ aflatoxin

In the peanut butter production plant we studied, the peanuts are roasted at $160^{\circ} \mathrm{C}$ followed by blanching. The greatest reduction of aflatoxin resulted from the roasting stage. An average of $51 \%$ of reduction of total aflatoxin was observed in contrast to studies in Brazil involving dry roasting in the laboratory and industry at $130^{\circ} \mathrm{C}$ which reported negligible reduction of aflatoxins. Ogunswanwo et al. [18] reported a mean $81.7 \%$ total aflatoxin reduction after roasting peanuts at $150^{\circ} \mathrm{C}$ for 30 minutes. That roasting reduces aflatoxin concentration significantly has also been reported in coffee production at the roasting stage [21] and in pistachio nuts [22].

Although the melting temperature is not reached during roasting, the roasting temperature is high enough to cause change in the aflatoxin chemical structure in a significant fraction of the peanuts thus reducing the concentration of the toxin. However, the percentage reduction was not correlated to the melting point of each toxin which is in the order $\mathrm{AFB}_{2}>\mathrm{AFB}_{1}>\mathrm{AFG}_{1}>\mathrm{AFG}_{2}$. It is worth noting that boiling aflatoxin contaminated peanuts in water has been reported to cause an approximately $80 \%$ aflatoxin reduction [17] whilst a reduction of $41 \%$ total aflatoxin has been reported after cooking meat from pigs fed an aflatoxin contaminated diet [23].

Blanching removed $27 \%$ of total aflatoxin indicating that a significant amount of the toxin is in the peanut skin. A combination of roasting and blanching removed $78 \%$ of total aflatoxins in the present study. This is in contrast to a report that the process of roasting and blanching reduces aflatoxin by just more than 50\% [24].

The contribution to the reduction of aflatoxins made by grinding was very little (3\% - 6\%) except for the reduction of $\mathrm{AFG}_{1}$ which was at $33 \%$. On average, the percentage reduction of total aflatoxin during grinding was $11 \%$. This reduction can be attributed to heat production during the grinding although the exact temperature attained was not measured. Global standards limit aflatoxin content in peanuts and/or products derived from peanuts at below $20 \mathrm{ng} \mathrm{g}^{-1}$ [25]. This study shows that processing can reduce aflatoxins to levels that are acceptable to many countries. It is, however, still imperative to determine the residual levels of aflatoxins in the peanut butter after processing in addition to pre-processing determination of the aflatoxin levels.

\section{Acknowledgements}

This work was supported by funds provided by the Research Board, National University of Science and Technology, Bulawayo, Zimbabwe.

\section{REFERENCES}

[1] W. P. Blount, “Turkey X Disease,” Journal of British Turkey Federation, Vol. 9, No. 52, 1961, pp. 52-61.

[2] R. C. Patten, “Aflatoxins and Disease,” American Journal of Tropical Medicine and Hygiene, Vol. 30, No. 2, 1981, pp. 522-425.

[3] D. L. Eaton and E. P. Callagher, "Mechanisms of Aflatoxin Carcinogenesis," Annual Review of Pharmacology and Toxicology, Vol. 34, No. 1, 1994, pp135-172. doi:10.1146/annurev.pa.34.040194.001031

[4] E. Azziz-Baumgartner, K. Lindblade, K. Gieseker, H. S. Rogers, S. Kieszak, H. Njapau, et al., "Case-Control Study of an Acute Aflatoxicosis Outberak, Kenya, 2004,” Environmental Health Perspectives, Vol. 113, No. 12, 2005. Internet Avaiable: http://ehp.niehs.nih.gov/members/2005/8384/384.html

[5] K. A. V. Krishnamachari, R. V. Bhat, V. Nagarajan and T. B. G. Tilak, "Investigation into an Outbreak of Hepatitis in Parts of Western India,” Indian Journal of Medical Research, Vol. 3, 1975, pp. 1026-1049.

[6] M. S. Lye, A. A. Ghazali, J. Mohan and N. Alwin, “An Outbreak of Acute Hepatitic Encelopathy due to Severe Aflatoxicosis in Malaysia," American Journal of Tropical Medicine and Hygiene, Vol. 53, 1995, pp. 68-72.

[7] C. A. Linsel and F. G. Peers, "Aflatoxin and Liver Cell Cancer," Transactions of the Royal Society of Tropical Medicine and Hygiene, Vol. 71, 1977, pp 471-473. doi:10.1016/0035-9203(77)90136-5

[8] International Agency for Research on Cancer (IARC), "IARC Monograms in the Evaluation of Carcinogenic Risks to Humans,” Aflatoxins, Vol. 56, 1993, pp. 245395.

[9] D. R. Katerere, G. S. Shephard and M. Faber, "Infant Malnutrition and Chronic Aflatoxocosis in Southern Africa: Is There a Link?” International Journal of Food Safety, Nutrition and Public Health, Vol. 1, No. 2, 2008 pp. 126-136.

[10] Y. Y. Gong, K. Cardwell, A. Hounsa, S. Egal, P. C. Turner and C. P. Wild, "Dietary Aflatoxin Exposure and Impaired Growth in Young Children from Benin and Togo: Cross Sectional Study,” British Medical Journal, Vol. 325, No. 7354, 2002, pp. 20-21. doi:10.1136/bmj.325.7354.20

[11] J. H. Williams, T. D. Philipps, P. E. Jolly, J. K. Stiles, C. M. Jolly and D. Aggarwal, "Human Aflatoxicosis in Developing Countries: A Review of Toxicology, Exposure, Potential Health Consequences and Interventions,” Ameri- 
can Journal of Clinical Nutrition, Vol. 80, No. 5, 2004, pp. 1106-1122.

[12] R. W. Beaver, "Decontamination of Mcotoxin-Containing Foods and Feedstuffs," Trends in Food Science and Technology, Vol. 2, 1991 pp. 170-173. doi:10.1016/0924-2244(91)90672-6

[13] H. F. Righter, W. T. Shalkop, H. D. Mercer and E. C. Leffel, "Influence of Age and Sexual Status on the Deveopment of Toxic Effects in the Male Rat Fed Aflatoxin," Toxicology and Applied Pharmacology, Vol. 21, 1972, pp. 435-439. doi:10.1016/0041-008X(72)90001-4

[14] R. D. Coker, B. D. Jones and M. J. Nagler, "Mycotoxin Training Manual,” Tropical Products Institute, London, 1982.

[15] A. H. Siwela, "Combined Use of Phenyl-Bonded Phase Clean-Up and HPLC for the Determination of Aflatoxins,” Tropical Science, Vol. 36, 1996, pp. 197-200.

[16] M. J. O’Neil, A. Smith and P. E. Heckelman, “The Merck Index,” 13th edition, Whitehouse Station, NJ, Merck \& Co. 2001, pp. 34-35.

[17] H. F Conway, R. A. Andersen and E. B. Bagley, "Decontamination of Corn by Roasting." Cereal Chemistry, Vol. 55, 1978, pp. 115-117.

[18] B. M. Ogunswanwo, O. O. P. Faboya, O. R. Idowu, O. S. Lawal and S. A Bankole, "Effect of Roasting on the Aflatoxin Contents of Nigerian Peanut Seeds,” African Journal of Biotechnology, Vol. 3, No. 9, 2004, pp. 451455.
[19] S. C. Basappa and F. Rehana, "Detoxification of Aflatoxin $\mathrm{B}_{1}$ in Maize by Different Cooking Methods,” Journal of Food Science and Technology, Vol. 27, 1990, pp. 397-399.

[20] D. B. Rodriguez-Amaya and M. Sabino, "Mycotoxin Research in Brazil: The Last Decade in Review,” Brazil Journal of Microbiology, Vol. 33, No. 1, 2002, pp. 1-11.

[21] K. M. Soliman, "Incidence, Level, and Behavior of Aflatoxin during Coffee Bean Roasting and Decaffeination," Journal of Agriculture and Food Chemistry, Vol. 50, 2002, pp. 7477-7481. doi:10.1021/jf011338v

[22] H. Yazdanpanah, T. Mohammadi, G. Abouhossain and A. M. Cheraghali, "Effect of Roasting on Degradation of Aflatoxins in Contaminated Pistachio Nuts," Food and Chemical Toxicology, Vol. 43, No. 7, 2005, pp. 11351139. doi:10.1016/j.fct.2005.03.004

[23] R. M. Furtado, A. M. Pearson, J. I. Gray, M. G. Hogberg and R. R Miller, "Effect of Cooking and/or Processing upon Levels of Aflatoxins in Meat from Pigs Fed a Contaminated Diet,” Journal of Food Science, Vol. 46, 2006, pp. 1306-1308. doi:10.1111/j.1365-2621.1981.tb04160.x

[24] M. Read, "Removal of Aflatoxin Contamination from the Australian Groundnut Crop,” In: S. D. Hall, Ed., Aflatoxin Contamination of Groundnut: Proceeding of the International Workshop, Patancheru, India, 1987, pp. 133 -140 .

[25] FAO, "Worldwide Regulations for Mycotoxins, 1995-A Compendium,” FAO Food and Nutrition, Rome, 1997. 